\title{
Perceived size and distance as a perceptual conflict between two processing modes
}

\author{
ATSUKI HIGASHIYAMA \\ Osaka City University, Sumiyoshi-ku, Osaka 558, Japan
}

\begin{abstract}
Three different sized squares were successively presented at the same physical distance under three observational conditions which provided different information about distance in the visual field. The 60 observers in each observational condition were asked to give verbal absolute judgments of perceived size and perceived distance for each of the squares. The results showed that in a full-cue situation a ratio of perceived absolute sizes is equal to that of the corresponding visual angles, with perceived distances appearing equal to each other; in a reduced-cue situation an object of smaller perceived size is judged to be farther away than one of larger perceived size, with the observers tending to assume the two objects as the same object or identically sized objects. These results were analyzed in terms of the perceptual conflict between primary perception and secondary perception.
\end{abstract}

The present study is concerned with the perception of size and distance in situations where similar objects with different visual angles are successively presented at the same physical distance from an observer. In these situations, there seems to be two processing modes which may produce a perceptual conflict.

One processing mode has been well documented as the traditional explanation of size constancy: the perceptual system transforms retinal image size into perceived size after registering distance information and taking into account registered distance or perceived distance. ${ }^{1}$ Oculomotor cues such as accommodation and convergence are the most relevant to this processing mode. For example, when convergence is decreased (increased) with no change of the retinal image size, the observer experiences the object as increasing (decreasing) in perceived size (Biersdorf, Ohwaki, \& Kozil, 1963; Heinemann, Tulving, \& Nachmias, 1959; Hermans, 1954; Holst, 1955a, 1955b; Leibowitz \& Moore, 1966; Oyama \& Iwawaki, 1972; Wallach \& Floor, 1971) and in perceived distance (Lie, 1965; Owens \& Leibowitz, 1976; Oyama, 1974; Swenson, 1932). This phenomenon suggests that the perceived size of the object depends on the registered distance or the perceived distance which occurs with changes of convergence. We shall refer to this processing mode as the primary perception. Suppose the situations in which two physically different sized objects, denoting the primary perceived absolute size of the larger object by ${ }_{I} S^{\prime}{ }_{L}$ and that of the smaller one by ${ }_{I} S^{\prime}$ 'S, are presented at the same physical distance. In this case, the primary perception predicts that a ratio of ${ }_{I} S^{\prime}{ }_{L}$ and ${ }_{I} S{ }_{S}$ is

\footnotetext{
The author is grateful to Dr. T. Ueno of Osaka City University for his critical reading of an earlier draft of this article.
}

equal to the corresponding ratio of the visual angles, $\Theta_{L}$ and $\Theta_{S}$, with the two primary perceived absolute distances, ${ }_{I} D^{\prime}{ }_{L}$ and ${ }_{I} D^{\prime} S$, appearing equal to each other, because the distance information resulting from oculomotor cues for the objects is entirely identical. In equational forms, the primary perception may be expressed as follows:

$$
\begin{aligned}
& {\left[\frac{{ }_{I} S^{\prime}{ }_{L}}{{ }_{I} S^{\prime} S}\right]=\frac{\Theta_{L}}{\Theta_{S}}} \\
& {\left[\frac{{ }_{I} D^{\prime}}{{ }_{I} D^{\prime}{ }_{S}}\right]=1,}
\end{aligned}
$$

where the subscript I represents the primary perception. It should be noted that Equations 1 and 2 are expressed in relative form. They imply nothing about absolute size and absolute distance per se, even if the observer can make absolute judgments of perceived size and distance. ${ }^{2}$

The relational perception of the two primary perceived sizes may be followed by the other processing mode: the perceptual system assumes that the object of smaller primary perceived size is farther away than the object of larger primary perceived size on the basis of a ratio (not a difference) of the two primary perceived sizes. This process may originate in the observer's tending to assume the two objects as the same object or identically sized objects despite the different appearance of the two primary perceived absolute sizes. We shall refer to this processing mode as the secondary perception.

The secondary perception has usually been considered to be explanatory for the effect of the relative size cue on perceived relative distance. A number of studies (Epstein, 1967; Gogel, 1964, 1969; Gogel \& 
Sturm, 1971; Ittelson, 1960) have indicated that the relative size cue has an effect on relative perceived distance when two objects of the same shape but different retinal sizes are presented simultaneously or successively in reduced-cue conditions. However, it seems premature to conclude from these studies that this cue can be defined in terms of relative retinal size, because the relational perception of the two primary perceived sizes, i.e., primary perceived relative size, may be interpreted to be crucial for the effect of the relative size cue on relative perceived distance. Although it is difficult to rule out either interpretation, the size-distance paradox provides a possible basis for a choice between the two. Biersdorf (1966), Grant (1942), and Heinemann et al. (1959) indicated that for some observers, when only the cues of accommodation and/or convergence are available, the physically near object of smaller perceived size is sometimes judged to be farther away than the physically far object of larger perceived size, despite the visual angle of the two objects' remaining constant. The crucial variable for triggering the sizedistance paradox, therefore, has been assumed to be primary perceived relative size (e.g., Biersdorf, 1966).

If we postulate that a ratio of the secondary perceived absolute distances, ${ }_{11} \mathrm{D}^{\prime}{ }_{\mathrm{L}} /{ }_{\mathrm{II}} \mathrm{D}_{\mathrm{S}}$, is equal to that of the two primary perceived absolute sizes, ${ }_{I} S^{\prime}{ }_{S}{ }_{I} S^{\prime}{ }_{L}$, and that the two objects are assumed to be equal in secondary perceived absolute size, then the secondary perception may be expressed as follows.

$$
\begin{gathered}
{\left[\frac{{ }_{I I} D^{\prime}{ }_{L}}{{ }^{\prime} D^{\prime}{ }_{S}}\right]=\left[\frac{{ }_{I} S^{\prime} S}{{ }_{I} S^{\prime}{ }_{L}}\right]=\frac{\theta_{S}}{\theta_{L}}} \\
{\left[\frac{{ }_{I I} S^{\prime} S_{L}}{{ }^{\prime} S_{S}}\right]=1,}
\end{gathered}
$$

where the subscript II represents the secondary perception. Note that Equations 3 and 4 are also defined in relative form.

The present investigation was undertaken to examine how the two processing modes are related to each other, depending on the distance cues in the visual field. The experiment was conducted in three different observational conditions, with the observers giving verbal absolute judgments of size and distance for three squares presented successively at the same physical distance. After transforming the reported absolute sizes and distances into relative sizes and distances, an attempt was made to analyze the data in terms of a perceptual conflict between primary perception and secondary perception.

\section{METHOD}

\section{Apparatus}

Figure 1 shows a schematic diagram of the apparatus. The apparatus consisted mainly of two units: the similar visual alleys $A_{1}$ and $A_{2}(22 \mathrm{~cm}$ high $\times 21 \mathrm{~cm}$ wide $\times 150 \mathrm{~cm}$ long) and $a$ viewing box with a half-mirror placed at $45^{\circ}$ against a viewing window. A frosted glass in the far portion of each visual alley was illuminated from behind by a white light bulb. The two alleys, as seen in Figure 1, were joined normally to the viewing box, so that a ray of light from the source in each visual alley, after passing through or being reflected by the half-mirror, reached the viewing window. The walls and the floor of visual alley $A_{1}$ were covered with black woolen paper, and its ceiling was formed by black drapery. Visual alley $\mathbf{A}_{2}$ was the same as $\mathbf{A}_{1}$ except that the floor consisted of a lateral striped pattern of red and white rectangles. The viewing box was equipped with a fall-type shutter used by experimenter to occlude the observer's view between stimulus presentations. The observational position was located in a darkened booth around the observer. None of the observers were thus acquainted with the magnitude of the apparatus extending beyond the booth.

\section{Stimulus Materials and Observational Conditions}

Stimulus targets were three different-sized white squares, made by cutting openings in pieces of cardboard. The squares were $1 \mathrm{~cm}$ (small size, $\mathrm{S}_{\mathrm{S}}$ ), $3 \mathrm{~cm}$ (middle size, $\mathrm{S}_{\mathrm{M}}$ ), and $5 \mathrm{~cm}$ (large size, $S_{L}$ ) on a side. They were presented one at a time in the visual alley $A_{1}$ at a distance of $106 \mathrm{~cm}$ from the observer. The observer viewed the squares transilluminated by the light through the openings in the cardboard.

The three squares were successively presented under the following three observational conditions: (1) The observer viewed the squares with both eyes in total darkness. Under this condition, he could make use of accommodation and convergence as well as the information of retinal image size. A $20-\mathrm{W}$ bulb served as light source. (2) An artificial pupil of $0.1 \mathrm{~cm}$ in diameter was inserted in the viewing window to allow the observer to view the squares with his right eye only. To compensate for the decrease in the brightness of the squares produced by the artificial pupil, a $40-\mathrm{W}$ bulb was driven with a voltage of 70 , so that the squares had the same brightness as that used in Condition 1. It should be noted that even in the second condition the observer could make use of accommodation and accommodative convergence, despite the restrictive aperture, as well as the information of retinal image size. Recently, Leibowitz and his colleagues (e.g., Owens \& Leibowitz, 1976) found in reducedcue conditions that both accommodation and convergence assume the resting state and that perceived distance is correlated with the resting state of convergence. (3) The observer viewed the squares binocularly in a fully illuminated alley. In this case, the black drapery forming the ceiling of visual alley $A_{2}$ was removed and the walls and floor of alley $A_{2}$ were illuminated by a white light bulb at the far end of the alley and by the fluorescent lamps on the ceiling of the experimental room. Visual alley $A_{1}$, on the other hand, was the same as that in Condition 1. The third arrangement produced a nearly natural viewing situation.

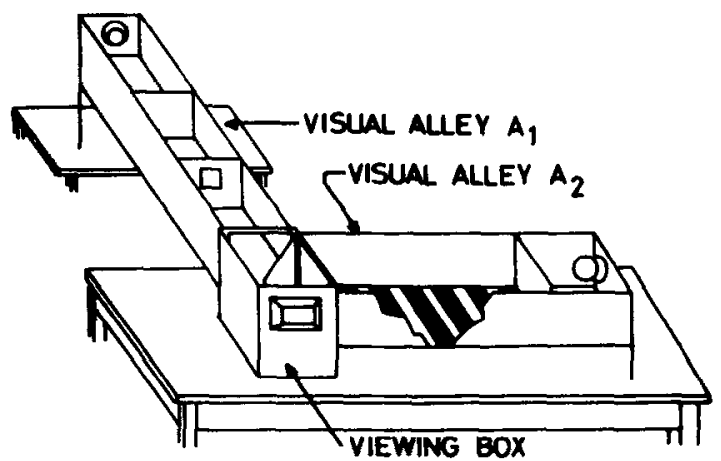

Figure 1. Schematic diagram of the apparatus. 


\section{Procedure}

The observers were tested individually. Each observer was led to the observational booth and seated in a chair. After 3 min dark adaptation, he was told to view the three squares presented one at a time. In addition, he was asked to indicate both the perceived size and the perceived distance of each square with verbal estimates expressed in meters, centimeters, or millimeters, or in some combination of them. The three squares were each presented for about $30 \mathrm{sec}$ with a $50-\mathrm{sec}$ intertrial interval.

\section{Observers}

The observers were 180 university students. Sixty observers were assigned randomly to each of the three conditions, with the restriction that 10 observers participate in each of the six presented sequences.

\section{RESULTS}

The verbal estimates of perceived absolute size and distance were transformed into ratios of the judgments for the large, middle, and small squares, according to Equations 1, 2, 3, and 4. Three estimated relative sizes, $S{ }_{L}{ }_{L} / S^{\prime}{ }_{S}, S{ }_{M} / S^{\prime} S$, and $S^{\prime}{ }_{L} / S^{\prime}{ }_{M}$, and three estimated relative distances, $D_{L}^{\prime} / D_{S}^{\prime}, D_{M}^{\prime} / D_{S}^{\prime}$, and $D_{L}^{\prime} / D_{M}^{\prime}$, were computed for each observer under each observational condition.

Table 1 indicates the arithmetic means, the median values, and the variances for the three estimated relative sizes under the three observational conditions, excluding the data of the observers who exceeded 10 in the value of estimated relative size. Hence the number of samples $(N)$ for each cell in Table 1 is not necessarily equal to 60 . The selection of the value of 10 as an excluding criterion seems to be necessary and sufficient in order to avoid biased data by some uncontrolled factors. Addition of such data distorted some of the smooth distributions which would usually be expected for judgments of perceived relative size.

According to Equations 1 and 4, the theoretical values for the primary perceived relative size are $S^{\prime}{ }_{L} / S^{\prime}{ }_{S}=5, S{ }^{\prime}{ }_{M} / S{ }^{\prime} S=3$, and $S{ }^{\prime}{ }_{L} / S^{\prime}{ }_{M}=$ 1.6667; for secondary perceived relative size, the theoretical value is equal to 1 in all three instances. The results reveal that as distance cues are eliminated in the visual field, the means of the estimated relative sizes shift from primary perceived relative size to secondary perceived relative size with increasing variance. In addition, the means show intermediate values between the two extreme predictions, except for the means of $S^{\prime}{ }_{L} / S^{\prime}{ }_{M}$ under the full-cue and monocular conditions. Such exceptions may be due to the imprecision of verbal judgments and the narrow range predicted from Equations 1 and 4 for $S^{\prime}{ }_{L} / S^{\prime} M$.

Table 2 indicates the arithmetic means, the median values, and the variances for the three estimated relative distances under the three observational con-
Table 1

Means, Medians, and Variances of Estimated Relative Size Under the Three Observational Conditions

\begin{tabular}{|c|c|c|c|c|}
\hline \multirow{3}{*}{ Condition } & & \multicolumn{3}{|c|}{ Estimated Relative Size } \\
\hline & & $\mathbf{S}_{\mathbf{L}}^{\prime}$ & $\mathbf{S}_{\mathbf{M}}^{\prime}$ & $\mathbf{S}_{\mathbf{L}}^{\prime}$ \\
\hline & & $\mathbf{S}_{\mathbf{S}}$ & $S_{S}^{\prime}$ & $\mathbf{S}_{\mathbf{M}}^{\prime}$ \\
\hline Full-cue & $\begin{array}{l}\text { Mean } \\
\text { Median } \\
\text { Variance } \\
\text { N }\end{array}$ & $\begin{array}{l}4.6847 \\
5.0000 \\
2.4222 \\
59\end{array}$ & $\begin{array}{r}2.7932 \\
3.0000 \\
59^{.6997}\end{array}$ & $\begin{array}{r}1.6810 \\
1.6667 \\
60^{.1937}\end{array}$ \\
\hline $\begin{array}{l}\text { Accommodation } \\
\text { and convergence }\end{array}$ & $\begin{array}{l}\text { Mean } \\
\text { Median } \\
\text { Variance } \\
\mathrm{N}\end{array}$ & $\begin{array}{l}3.5319 \\
4.0000 \\
2.7985 \\
59\end{array}$ & $\begin{array}{r}2.3439 \\
2.5000 \\
59 \\
59678\end{array}$ & $\begin{array}{r}1.4542 \\
1.4286 \\
60^{.2643}\end{array}$ \\
\hline $\begin{array}{l}\text { Monocular through } \\
\text { pinhole }\end{array}$ & $\begin{array}{l}\text { Mean } \\
\text { Median } \\
\text { Variance } \\
\text { N }\end{array}$ & $\begin{array}{l}3.3957 \\
3.1667 \\
3.6358 \\
53\end{array}$ & $\begin{array}{l}2.1936 \\
2.0000 \\
2.1936 \\
55\end{array}$ & $\begin{array}{r}1.6708 \\
1.5850 \\
.6121 \\
59\end{array}$ \\
\hline
\end{tabular}

ditions. In making the calculations, not included were the data of estimated relative distance that corresponded to the data of the observers eliminated in analyzing the results of estimated relative size. According to Equations 2 and 3, the theoretical value for the primary perceived relative distance is equal to 1 in all three cases; for the secondary perceived relative distance, the theoretical values are $D^{\prime}{ }_{L} / D^{\prime} S$ $=0.2000, \mathrm{D}^{\prime}{ }_{\mathrm{M}} / \mathrm{D}^{\prime} \mathrm{S}=0.3333$, and $\mathrm{D}^{\prime}{ }_{\mathrm{L}} / \mathrm{D}^{\prime}{ }_{\mathrm{M}}=$ 0.6000 . The results indicate a general tendency similar to the results for estimated relative size: As distance cues are eliminated, the means of estimated relative distance have a tendency to shift from primary perceived relative distance to secondary perceived relative distance with increasing variance. In addition, the means also show intermediate values between the two extreme predictions.

Table 2

Means, Medians, and Variances of Estimated Relative Distance Under the Three Observational Conditions

\begin{tabular}{|c|c|c|c|c|}
\hline \multirow{3}{*}{ Condition } & & \multicolumn{3}{|c|}{ Estimated Relative Distance } \\
\hline & & $D_{L}^{\prime}$ & $\mathrm{D}_{\mathbf{M}}^{\prime}$ & $D_{L}^{\prime}$ \\
\hline & & $\mathrm{D}_{\mathrm{S}}^{\prime}$ & $\mathrm{D}_{\mathbf{S}}^{\prime}$ & $\mathrm{D}_{\mathbf{M}}^{\prime}$ \\
\hline Full-cue & $\begin{array}{l}\text { Mean } \\
\text { Median } \\
\text { Variance } \\
\mathrm{N}\end{array}$ & $\begin{array}{r}.9014 \\
1.0000 \\
59^{.0825}\end{array}$ & $\begin{array}{r}.9192 \\
1.0000 \\
59^{.0753}\end{array}$ & $\begin{array}{r}.9717 \\
1.0000 \\
.1092 \\
60\end{array}$ \\
\hline $\begin{array}{l}\text { Accommodation } \\
\text { and convergence }\end{array}$ & $\begin{array}{l}\text { Mean } \\
\text { Median } \\
\text { Variance } \\
\mathbf{N}\end{array}$ & $\begin{array}{r}.5320 \\
.5000 \\
.0659\end{array}$ & $\begin{array}{r}.7180 \\
.6667 \\
59^{.1228}\end{array}$ & $\begin{array}{r}.7462 \\
.7500 \\
.1104 \\
60\end{array}$ \\
\hline $\begin{array}{l}\text { Monocular through } \\
\text { pinhole }\end{array}$ & $\begin{array}{l}\text { Mean } \\
\text { Median } \\
\text { Variance } \\
\text { N }\end{array}$ & $\begin{array}{r}.5049 \\
.4688 \\
.2234 \\
53\end{array}$ & $\begin{array}{r}.6967 \\
.6000 \\
.3178\end{array}$ & $\begin{array}{r}.8171 \\
.6667 \\
.2593 \\
59\end{array}$ \\
\hline
\end{tabular}




\section{DISCUSSION}

Although other interpretations are possible, these results are consistent with an interpretation in terms of conflict between perceptual processing modes.

\section{Perceptual Compromise}

Perception of relative size and distance may be regarded as a compromise between primary perception and secondary perception. The observer may experience a perceptual conflict between the two processing modes, resolve the conflict in some way, and then report the resultant percept as a verbal estimate. Ittelson (1960) suggested two classes for the resolution of perceptual conflict, which can be labeled compromise resolution and suppression resolution. Compromise resolution represents the type in which the resultant percept is neither one alternative nor the other but is a compromise between the two, while suppression resolution represents the type in which the resultant percept coincides with one of the alternatives. The present results seem to favor the mode of compromise resolution between the primary and secondary perceptions: (1) The means for estimated relative size and distance, as seen in Tables 1 and 2, show generally intermediate values between the predictions based on the primary perception and the predictions based on the secondary perception. (2) The means for estimated relative size and distance shift gradually with the changes in information about distance.

\section{Probabilistic Approach}

We have hitherto defined the two processing modes in the algebraic manner in Equations 1, 2, 3, and 4. However, the algebraic definition may not be as appropriate as a probabilistic definition for describing the processing modes. We redefine the primary and the secondary perceptions as follows: For primary perception,

$$
E\left[\frac{{ }_{I} S^{\prime}{ }_{L}}{{ }^{\prime}{ }^{\prime} S}\right]=\frac{\Theta_{L}}{\Theta_{S}}, \quad E\left[\frac{{ }_{I} D_{L}^{\prime}}{{ }_{I} D^{\prime}{ }_{S}}\right]=1,
$$

and for secondary perception,

$$
E\left[\frac{{ }_{I I} D^{\prime}{ }_{L}}{{ }_{I I} D^{\prime}{ }_{S}}\right]=\frac{\Theta_{S}}{\Theta_{L}}, \quad E\left[\frac{{ }_{I I} S^{\prime}{ }_{L}}{{ }_{I I} S^{\prime}}\right]=1,
$$

where $E$ represents an expected value of the estimated relative size and distance.

An example of the simplest equation expressing the mode of compromise resolution is that for the estimated relative size, $S^{\prime}{ }_{L} / S^{\prime}{ }_{S}$.

$$
\left[\frac{S^{\prime}{ }_{L}}{S^{\prime}{ }_{S}}\right]=p\left[\frac{{ }^{S^{\prime}}{ }_{L}}{{ }_{I} S^{\prime}}\right]+(1-p)\left[\frac{{ }_{I I} S^{\prime}}{{ }_{I I} S^{\prime} S}\right]
$$

where $p$ and $(1-p)$ are positive constants $(0 \leqslant p$ $\leqslant 1$ ), depending on observational conditions, and are the relative weights given to primary perceived relative size and secondary perceived relative size, respectively. If we postulate independence of the two processing modes, then the mean and the variance can be stated from Equation 7:

$$
\begin{aligned}
& E\left[\frac{S^{\prime}{ }_{L}}{S^{\prime}{ }_{S}}\right]=p \quad E\left[\frac{{ }_{I} S_{L}^{\prime}}{{ }_{I}{ }_{S}}\right]+(1-p) E\left[\frac{{ }_{I I} S^{\prime}{ }_{L}}{{ }_{I I}{ }^{\prime}{ }_{S}}\right] \\
& V\left[\frac{S_{L}^{\prime}}{S^{\prime}{ }_{S}}\right]=p^{2} V\left[\frac{{ }_{I} S_{L}^{\prime}}{{ }_{I}{ }^{\prime}{ }_{S}}\right]+(1-p)^{2} V\left[\frac{{ }_{I I} S^{\prime}{ }_{L}}{{ }_{I I} S_{S}}\right]
\end{aligned}
$$

If we assume that Equations 5 and 6 hold, then the value of $\mathrm{p}$ can be readily computed from Equation 8 for each of the three observational conditions. The value of $p$ for $S^{\prime}{ }_{L} / S^{\prime}{ }_{S}$ under the full-cue condition, for example, is 0.9212 , since $E\left(S^{\prime}{ }_{L} / S^{\prime}{ }_{S}\right)$ obtained under this condition is 4.6847 , as shown in Table 1 . The $p$ values for the other estimated relative sizes, $S^{\prime}{ }_{M} / S^{\prime}{ }_{S}$ and $S^{\prime}{ }_{L} / S^{\prime}{ }_{M}$, computed in the same way for each of the three observational conditions, are summarized in Table 3. Two of the three $p$ values for $S^{\prime}{ }_{L} / S^{\prime}{ }_{M}$ could not be obtained since they were greater than 1 . The failure of estimating the two $p$ values need not necessarily be interpreted as a strike against the model of perceptual compromise. An examination of the raw data suggested clearly that the failure can be attributed to the response bias in verbal judgments rather than to the perceptual process, such as preference for integral numbers over decimal fractions. Thus, if more refined techniques are applied in order to estimate perceived relative size, all the $p$ values would be expected to fall within

\begin{tabular}{|c|c|c|c|c|}
\hline \multirow{3}{*}{\multicolumn{2}{|c|}{ Condition }} & \multicolumn{3}{|c|}{ Estimated Relative Size } \\
\hline & & \multirow{2}{*}{$\frac{S_{L}^{\prime}}{S_{S}^{\prime}}$} & \multirow{2}{*}{$\frac{S_{M}^{\prime}}{S_{S}^{\prime}}$} & \multirow{2}{*}{$\frac{S_{L}^{\prime}}{S_{M}^{\prime}}$} \\
\hline & & & & \\
\hline \multirow{3}{*}{\multicolumn{2}{|c|}{$\begin{array}{l}\text { Full-cue } \\
\text { Accommodation and convergence } \\
\text { Monocular through pinhole }\end{array}$}} & .9212 & .8966 & $*$ \\
\hline & & .6330 & .6718 & .6820 \\
\hline & & .5989 & .5978 & * \\
\hline Variance & I & 2.7045 & .8129 & $*$ \\
\hline
\end{tabular}
the range: $0 \leqslant p \leqslant 1$.

Table 3

$P$ Values and Pairs of Variances Computed from Equations 8 and 9 for Estimated Relative Size

Note-An asterisk represents cases in which $p$ value or variance was not obtained from Equation 8 or Equation 9. 
The values of $\mathrm{V}\left({ }_{\mathrm{I}} \mathrm{S}_{\mathrm{L}} /{ }_{\mathrm{I}} \mathrm{S}^{\prime} \mathrm{S}\right)$ and $\mathrm{V}\left({ }_{\mathrm{II}} \mathrm{S}^{\prime}{ }_{\mathrm{L}} /{ }_{\mathrm{II}} \mathrm{S}^{\prime} \mathrm{S}\right)$ can be computed from Equation 9. If we assume that $\mathrm{V}\left({ }_{\mathrm{I}} \mathrm{S}^{\prime}{ }_{\mathrm{L}} / \mathrm{I}_{\mathrm{I}} \mathrm{S}_{\mathrm{S}}\right)$ and $\mathrm{V}\left({ }_{\mathrm{II}} \mathrm{S}_{\mathrm{L}}{ }_{\mathrm{JJ}} \mathrm{S}{ }^{\prime} \mathrm{S}\right)$ are constant and independent of the information about distance in the visual field, then it is possible to estimate the variances as multiple linear regression coefficients by using both the values of $p^{2}$ and $(1-p)^{2}$ computed for the three observational conditions and the variances of $S^{\prime}{ }_{L} / S^{\prime}{ }_{S}$ corresponding to them. As a result, $\mathrm{V}\left(\mathrm{S}^{\prime}{ }_{\mathrm{L}} / \mathrm{I}_{\mathrm{I}} \mathrm{S}_{\mathrm{S}}\right)$ and $\mathrm{V}\left({ }_{\mathrm{II}} \mathrm{S}_{\mathrm{L}}{ }_{\mathrm{II}} \mathrm{I}^{\prime}{ }_{\mathrm{S}}\right)$ were 2.7045 and 14.9938, respectively. The pair of the variances for $S^{\prime}{ }_{L} / S^{\prime}{ }_{M}$ could not be estimated due to the loss of the two $p$ values. The variances thus computed are presented in the last row in Table 3.

For the mode of compromise resolution for the estimated relative distance $D^{\prime}{ }_{L} / D^{\prime} S$, the appropriate equations can be formed by substituting $D^{\prime}$ for $S^{\prime}$ in Equations 7, 8, and 9. With the same method as mentioned above, we can estimate the values of $p$, $(1-p), V\left({ }_{I} D^{\prime}{ }_{L} /{ }_{I} D^{\prime} s\right)$, and $V\left({ }_{I I} D^{\prime}{ }_{L} /{ }_{I I} D^{\prime} s\right)$. Table 4 shows the values of $p$ and the three pairs of variances.

Two conclusions can be generally drawn from Table 3 and 4: (1) The values of $p$ decrease with elimination of the distance cues in the visual field. That is, the primary perception is exerted more dominantly in a full-cue situation, whereas the secondary perception is exerted more strongly in a reduced-cue situation. (2) The variances of the secondary perceived relative sizes and distances are estimated to be several times as large as those of the primary perceived relative sizes and distances. If the estimated variances can be considered as representing the stability of a processing mode, then the primary processing mode is more stable than the secondary one.

The study of perceptual conflict or cue conflict has a long and continuing history (e.g., Epstein, 1967, p. 165), some of which can be related to the results of the present experiment. Ittelson (1960) has performed several experiments on perceptual conflict, one of which is relevant to the conflict between binocular disparity and the relative size cue to perceived distance. The results indicated that the large difference in visual angle for the presented rectangles

Table 4

$P$ Values and Variances for Estimated Relative Distance

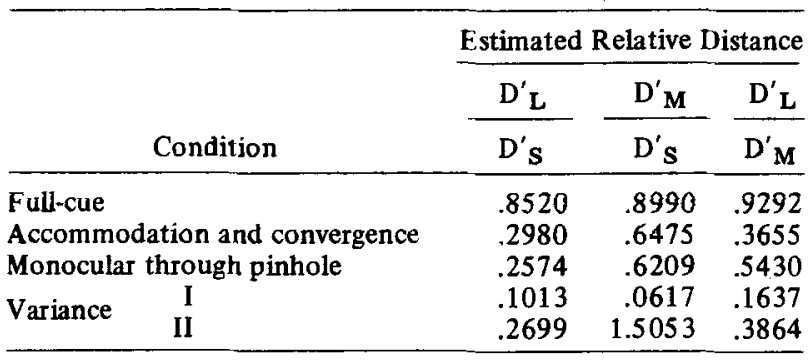

reduced the influence of binocular disparity, strengthening the effect of the relative size cue on perceived distance. The results in Table 2 are consistent with this conclusion, since the values of the estimated relative distances decrease as the ratios of the visual angles deviate from 1 for a given observational condition. Gogel and Sturm (1972) reported a similar experiment under the two observational conditions. Their results indicated that the relative size cue was more effective for monocular (accommodative convergence) than for binocular (fusional convergence) observation. The results in Tables 1 and 2 are also in agreement with this conclusion.

\section{REFERENCES}

Biersdorf, W. R. Convergence and apparent distance as correlates of size judgments at near distances. Journal of General Psychology, 1966, 75, 249.264.

Biersdorf, W. R., OHwaki, S., \& KoziL, D. J. The effect of instructions and oculomotor adjustments on apparent size. American Journal of Psychology, 1963, 76, 1-17.

EpSTEIN, W. Varieties of perceptual learning. New York: McGraw-Hill, 1967.

Goger, W. C. Size cue to visually perceived distance. Psychological Bulletin, 1964, 62, 217.235.

GoGEL. W. C. The sensing of retinal size. Vision Research, 1969 , 9. 1079-1094

Gogel, W. C., \& Sturm, R. D. Directional separation and the size cue to distance. Psychologische Forschung, 1971, 35, 57-80.

Gogel, W. C., \& StURM. R. D. A comparison of accommodative and fusional convergence as cues to distance. Perception \& Psychophysics, 1972, 11, 166-168.

GRANT, V. W. Accommodation and convergence in visual space perception. Journal of Experimental Psychology, 1942, 31, 89-104.

Heinemann, E. G., Tulving, E., \& Nachmias, J. The effect of oculomotor adjustments on apparent size. American Journal of Psychology, 1959, 72, 32-45.

Hermans. T. G. The relationship of convergence and elevation changes to judgments of size. Journal of Experimental Psychology, 1954, 48. 204-208.

Holst, E. von. Die Beteiligung von Konvergenz und Akkommodation an der wahrgenommenen Grössenkonstanz. Naturwissenschaften, 1955, 42, 444-445. (a)

Holst, E. von. Ist der Einfluss der Akkommodation auf die gesehene Dinggrösse ein "reflektorischer" Vorgang? Naturwissenschaften, 1955, 42, 445-446. (b)

Ittelson, W. H. Visual space perception. New York: Springer, 1960.

Leibowitz, H.. \& MOORE, D. Role of changes in accommodation and convergence in the perception of size. Journal of the Optical Society of America, 1966, 56, 1120-1123.

LiE, I. Convergence as a cue to perceived size and distance. Scandinavian Joumal of Psychology, 1965, 6, 109-116.

OWENs. D. A., \& Leinowrtz, H. W. Oculomotor adjustments in darkness and the specific distance tendency. Perception \& Psychophysics, 1976, 20, 2-9.

Oy ama. T. Perceived size and perceived distance in stereoscopic vision and an analysis of their causal relations. Perception \& Psychophysics, 1974, 16, 175-181.

OYAMA. T., \& IWAWAKI, S, Role of convergence and binocular disparity in size constancy. Psychologische Forschung, 1972, 35. 117-130.

Rock, I. An introduction to perception. New York: Macmillan, 1975.

SwENSON, H. A. The relative influence of accommodation 
and convergence in the judgment of distance. Joumal of General Psychology, 1932, 7, 360-380.

Wallach, H., \& Floor, L. The use of size matching to demonstrate the effectiveness of accommodation and convergence as cues for distance. Perception \& Psychophysics, 1971, 10, 423-428.

\section{NOTES}

1. Wallach and Floor (1971) have defined registered distance succinctly: registered distance is a theoretical term denoting the representation of distance in the nervous system usually resulting from the available cues for distance. The observer cannot experience registered distance directly at a conscious level, despite the fact that the information about distance is registered in the brain. On the other hand, perceived distance is defined as distance attained at a conscious level, which is also affected by conditions other than cues for distance. Rock (1975) has similarly distinguished between registered distance and perceived distance.

2. The expression perceived relative size or perceived relative distance is used in this paper to indicate a ratio of two perceived absolute sizes or two perceived absolute distances. On the other hand, perceived absolute size is referred to as perceived size of the presented object in itself; perceived absolute distance is referred to as perceived distance of the object from observer.

(Received for publication February 7, 1977; revision accepted May 23, 1977.) 